\title{
O PRECARIADO COMO CATEGORIA SOCIOLÓGICA INTERPRETATIVA DA REFORMA TRABALHISTA BRASILEIRA NO CONTEXTO DA FLEXIBILIZAÇÃO CONTEMPORÂNEA DO DIREITO DO TRABALHO
}

\author{
THE PRECARIAT AS AN INTERPRETATIVE SOCIOLOGICAL CATEGORY OF THE LABOR
} REFORM IN THE CONTEXT OF CONTEMPORARY FLEXIBILIZATION OF LABOR LAW

Gabriel de Oliveira de Mello ${ }^{1}$ Universidade Federal do Paraná (UFPR) Abili Lázaro Castro de Lima Universidade Federal do Paraná (UFPR)

\begin{abstract}
Resumo:
A recente reforma trabalhista, implementada pelas Leis $n^{\circ} 13.429 / 2017$ e 13.467/2017, tanto qualitativa quanto quantitativamente representou um marco no direito do trabalho brasileiro. Em razão de sua relevância, convém não apenas analisá-la segundo o ferramental dogmático, sendo especialmente frutífero o diálogo que se pode estabelecer com a sociologia. Nesse sentido, a adoção conceitual do que se vem chamando de precariado no estudo das classes sociais, em consonância com as especificidades latino-americanas, contribui para evidenciar uma face um tanto obscura - apesar de ambígua - desse fenômeno: embora possa contribuir para a redução da informalidade e a diminuição do desemprego, a flexibilização da legislação laboral responde a um ethos em cujo contexto está a crescente precariedade do trabalho e da vida.
\end{abstract}

Palavras-chave

Reforma trabalhista. Flexibilização do direito do trabalho. Precariado. Globalização. Neoliberalismo.

\begin{abstract}
The recent Labor Reform Act of 2017 (Acts $n^{\circ}$ 13.429/2017 and 13.467), represented both qualitatively and quantitatively a milestone in Brazilian labor law. Due to the theme's relevance and the fruitful dialogue that can be established between law and sociology, it may be insufficient analyzing it only according to the dogmatic perspective. In this regard, the conceptual adoption of what has been called by some authors as "the precariat", in consonance with Latin-American specificities, contributes to demonstrate a somewhat obscure - although ambiguous - aspect of this phenomenon: regardless of its possible contribution to the decreasing of unemployment and labor informality, the flexibilization of labor law responds to an ethos in the context of which is the growing precariousness of work and life.
\end{abstract}

Keywords

Labor reform. Flexibilization of labor law. The precariat. Globalization. Neoliberalism.

\section{NOTAS INTRODUTÓRIAS}

É inegável a magnitude das transformações engendradas pela chamada reforma trabalhista no ordenamento jurídico brasileiro. Implementada pelas leis n $n^{\text {o }}$ 13.429/2017 e 13.467/2017, ela provocou a alteração de mais de 100 artigos da Consolidação das Leis do Trabalho, ensejando mutações significativas no disciplinamento das relações laborais individuais, coletivas e processuais.

\footnotetext{
${ }^{1}$ Mestrando no Programa de Pós-Graduação em Direito da Universidade Federal do Paraná.

${ }^{2}$ Professor do Programa de Pós-Graduação em Direito da Universidade Federal do Paraná.
} 
Capitaneadas pelo Poder Executivo, tais inovações legislativas ficaram marcadas como "uma das medidas mais importantes" do governo cujo ciclo encerrou-se em 2019, sendo benquistas consoante o ponto de vista do empresariado, de parte significativa da mídia e dos políticos que constituíam a base de apoio do governo Temer pelo potencial de operarem a "modernização das relações de trabalho", bem como por conectarem "o mundo do trabalho no Brasil ao século 21", como bem destacado em discurso do então Presidente no dia 11/11/2017 (REFORMA..., 2017). Perceptível, portanto, a relevância macroeconômica dessa reforma, tida como crucial para a diminuição do desemprego e retomada do desenvolvimento.

A disputa interpretativa por muitos dos dispositivos recém-promulgados segue intensa nas searas judicial e científica, confrontando-se diferentes visões de mundo e de direito de juízes, professores, advogados e procuradores, especialmente no que toca à constitucionalidade das inovações legais. ${ }^{3}$

De outra banda, para além dessas profícuas discussões dogmáticas, entende-se como oportuno fomentar reflexões interdisciplinares sobre a temática, notadamente com as ciências sociais, sobretudo porque o direito não apenas regula a vida social mas igualmente é produto dela e, nesse diapasão, torna-se fundamental a análise das consequências sociais dos fenômenos jurídicos.

A flexibilização do direito do trabalho que avulta na reforma legislativa em apreço não é novidade no Brasil ou no mundo. Pelo contrário, é um fenômeno fruto da globalização econômica, da reestruturação produtiva e do acirramento da competição nacional e internacional nos mercados que desfiguram premissas consagradas desse ramo especializado do direito privado - e isso basicamente dos anos 1970 em diante.

Por isso, sociólogos brasileiros e estrangeiros têm se dedicado a compreender como as necessidades do mercado globalizado por um regime jurídico-trabalhista flexível - bem como a premência dos Estados em acatar essas necessidades - vem afetando o conjunto de pessoas que necessitam vender a força de trabalho em troca de salário para sobreviver. Nesse contexto, é oportuna a chave interpretativa produzida pelo sociólogo britânico Guy Standing, notadamente nos seus estudos sobre a configuração contemporânea das classes sociais.

Conforme será explicado no item 2, o referido autor alerta que as transformações jurídico-econômicas dos arranjos tradicionais do labor humano, levadas a cabo por políticas

\footnotetext{
${ }^{3}$ Parte importante das inovações legais já foi ratificada pelo STF, como é o caso da terceirização irrestrita, analisada pelo colegiado quando do julgamento da ADPF 324 e do RE 958252, e do fim da contribuição sindical obrigatória, analisada pelos ministros no julgamento da ADI 5794. Entretanto, a grande maioria das novidades ainda será passível de julgamento pela corte constitucional, já que diversas ações tramitam no tribunal com essa finalidade.
} 
específicas, têm por efeito o surgimento de uma nova classe perigosa, a saber, o precariado, composta por trabalhadores assolados pela falta de estabilidade, pela insegurança e permanente ansiedade, diferentemente dos empregados típicos do regime de acumulação fordista.

O item 3 se destina a recortar e lapidar o conceito de precariado sob a ótica jurídica, levando em consideração as peculiaridades socioeconômicas de um país periférico como o Brasil, sobretudo a partir de estudiosos locais, como Ruy Braga e Ricardo Antunes, o que possibilitará, no item 4, a identificação isolada dos principais pontos da reforma trabalhista brasileira que podem contribuir para a expansão desse grupo de pessoas.

Como se pode deduzir dessas notas introdutórias, não existe qualquer intenção de apreender juridicamente os efeitos dogmáticos da reforma trabalhista. Ao revés, objetiva-se demonstrar, pelas lentes sociológicas do precariado, como a malha jurídico-institucional do Estado pode vir a ter um papel central na remodelação do modo de viver do cidadão e, em última instância, da própria sociedade.

Com efeito, tendo-se estabelecido a atualidade e a importância do tema, bem como o intento de se aproximar direito do trabalho e sociologia na busca de diferentes interpretações dos fenômenos políticos e sociais contemporâneos, utilizar-se-á o método dedutivo mediante ampla revisão bibliográfica para o alcance dos objetivos acima delineados.

\section{PRECARIADO E PRECARIZAÇÃO ESTRUTURAL DO TRABALHO GLOBAL}

Não há outra maneira de enfatizar objeto de estudo senão recorrendo aos estudos sociológicos de Guy Standing, autor que defende a polêmica noção de que o precariado constituiria uma nova classe, diferente da famosa classe trabalhadora, imortalizada no campo das ideias como o proletariado, sobretudo a partir do pensamento marxiano.

Standing (2014a, p. 14-19) se refere ao precariado como um grupo composto por milhões de pessoas "sem uma âncora de estabilidade" e cujas principais características seriam a precariedade de moradia, trabalho, emprego e proteção social. No mesmo sentido, enquadralhe como classe emergente marcada pela insegurança crônica e apartada das velhas normas trabalhistas, o que estaria corroendo o status de cidadão (citizens) de seus integrantes, tidos agora como meros habitantes (denizens) sensíveis a políticas populistas que lucram com essa instabilidade (STANDING, 2014a, p. 15).

De pronto já é perceptível a ambiguidade do fenômeno: a precariedade não deve ser vista somente pelos seus dissabores, já que muitos indivíduos simplesmente não desejam os ônus e os bônus da sociedade industrial e do trabalhismo do século XX. Ademais, como aponta 
Standing, o precariado não se confunde com o trabalhador pobre ou o emprego incerto - embora tais dimensões lhe sejam correlativas -, já que também “implica a falta de uma identidade segura baseada no trabalho" ou a completa falta de perspectiva sobre a progressão de carreira (STANDING, 2014b, p. 27).

Em outras palavras, a precariedade da vida é mais do que uma situação conjuntural, na medida em que compõe, em termos weberianos, o "espírito" do capitalismo contemporâneo (WEBER, 2004). ${ }^{4}$ Nessa mesma esteira, Boltanski e Chiapello (2009, p. 91-117) argumentam que a subjetividade do trabalhador foi paulatinamente moldada por exigências do discurso empresarial dos anos 1990, passando do estímulo ao progresso e da certeza na carreira, típicos dos anos 1960, para a ênfase na realização pessoal graças à multiplicidade de projetos.

Esse novo "espírito" do capitalismo é apresentado pelos ideólogos como libertação, tendo como palavras de ordem a criatividade, reatividade e flexibilidade: dos anos $1990 \mathrm{em}$ diante, passa-se a valorizar aqueles que sabem trabalhar em projetos, como líderes ou colaboradores, obreiros abertos, flexíveis e polivalentes, aptos a adaptarem-se permanentemente (BOLTANSKI; CHIAPELLO, 2009, p. 123-124). É essa, portanto, a raiz da ambiguidade acima referida.

Nada obstante, é notável que o precariado tem o "lado vítima" muito mais saliente seu que o "lado herói”, como admite o próprio Standing. É que a insegurança crônica corrói a capacidade de planejamento e a estabilidade pessoal e familiar, engendrando disfuncionalidades sociais diversas.

É pensando nisso que o autor em apreço define formalmente o precariado como o grupo de pessoas - uma classe ${ }^{5}$ em formação - desprovidas de sete formas de garantia relacionadas ao trabalho e perseguidas pelos socialdemocratas como agenda de "cidadania industrial": 1) garantia de mercado de trabalho; 2) garantia de vínculo empregatício; 3) segurança no emprego; 4) segurança do trabalho; 5) garantia de reprodução de habilidade; 6) segurança de renda; 7) garantia de representação (STANDING, 2014b, p. 28-29).

Quer isso dizer que: 1) não mais se intenta oferecer ao trabalhador oportunidades adequadas de renda-salário, embora teoricamente haja a busca do pleno emprego; 2) afrouxa-

\footnotetext{
${ }^{4}$ Max Weber foi o primeiro autor clássico a abordar o capitalismo não como sistema econômico ou modo de produção, mas sim como "espírito", como cultura, como modo de vida subjetivo.

${ }^{5}$ Argumenta Standing (2014b, p. 24-25) que a globalização pós-guerra ensejou mundialmente uma estrutura de classe mais fragmentada do que aquela do século XIX: 1) no topo encontra-se uma "elite" bilionária de cidadãos globais; 2) abaixo da elite encontram-se os "assalariados" com emprego estável e integral; 3) ao lado dos últimos localiza-se, em menor número, os proficians, isto é, pessoas com habilidades profissionais que são vendidas de forma rentável de modo autônomo; 4) abaixo destes aparece a "velha classe trabalhadora" típica do Estado de bem-estar; 5) por fim, na base da pirâmide, exsurge o precariado flanqueado pelo exército de desempregados.
} 
se o grau de proteção à integridade do vínculo empregatício e os incentivos para que os empregadores efetivamente cumpram as normas trabalhistas; 3) dificulta-se cada vez mais a continuidade no emprego e as possibilidades de mobilidade ascendente em termos de renda e status; 4) dilui-se a imperatividade de regras referentes à segurança e saúde laborais. Paralelamente, 5) são enfraquecidas as oportunidades de se adquirir habilidades através de estágios, cursos e treinamentos, assim como a oportunidade de fazer uso de novos conhecimentos; 6) a garantia de uma renda adequada, estável e protegida, bem como de uma previdência social abrangente, é pouco a pouco obliterada; 7) debilita-se o poder coletivo de barganha dos trabalhadores mediante ataques aos seus entes representativos.

Bourdieu (1998, p. 74), ao fim da década de 1990, foi um dos primeiros sociólogos a articular o lado negativo de toda essa instabilidade, afirmando que "a precariedade está hoje por toda a parte”, espraiando-se do setor privado ao público e vice-versa, multiplicando-se funções temporárias e interinas, desestruturando a existência, remodelando os sentidos de tempo e espaço. Ela incide diretamente sobre os afetados e indiretamente sobre todos os outros pelo temor que suscita.

A longo prazo, a precariedade inviabiliza qualquer vestígio de ação racional, teorizada por Weber (2004) ${ }^{6}$, porquanto a falta de estabilidade aniquila a capacidade de cálculo econômico e também qualquer mobilização transformadora, já que a transformação da perspectiva futura exige o mínimo de domínio sobre o presente (BOURDIEU, 1998, p. 73). Não por acaso, Sennet (1999) demonstrou como se conectam intimamente a precariedade, a corrosão da identidade e a anomia social.

Standing (2014b, p. 49) aponta que, para se compreender as causas do crescimento do precariado, é preciso conceber a natureza da "transformação global" (global transformation), isto é, a globalização pós-Segunda Guerra e a operacionalização da sua dimensão econômica pelas políticas de cunho neoliberal. De fato, na esteira das teorizações de Pierre Bourdieu, "a precariedade é produto de uma vontade política" e não de uma fatalidade econômica, estando intimamente ligada às estratégias empresariais de flexibilidade (BOURDIEU, 1998, p. 74).

De modo próximo à concepção de Standing, pode-se entender a globalização através de um tipo ideal, como "uma crescente interconexão em vários níveis da vida cotidiana a diversos lugares longínquos do mundo", conceito que transparece sua multidimensionalidade, isto é, seu reflexo nas searas política, social, ambiental, cultural e econômica. Nesse contexto, a dimensão

\footnotetext{
${ }^{6}$ Weber considerava como o ofício do sociólogo desvendar o sentido da ação social. Assim, mediante a utilização da ferramenta metodológica do tipo ideal, o autor argumentava que a ação social racional orientada a fins e a valores preponderam na modernidade, com o progressivo desencantamento do mundo.
} 
econômica, fomentada por políticas neoliberais, seria o fio condutor das demais dimensões (LIMA, 2002, p. 139).

Não por outro motivo, Kallenberg (2009, p. 22) afirma que o trabalho precário das últimas décadas seria resultado do crescimento da globalização (interdependência econômica e seus correlatos) e da expansão do neoliberalismo (políticas de desregulação, privatização e remoção de proteções sociais), engendrados por uma recente revolução tecnológica paralela ao decrescimento dos sindicatos e ao recrudescimento do individualismo.

A globalização econômica tem como principais atores as empresas transnacionais e como um de seus principais resultados a nova divisão internacional do trabalho. De acordo com a leitura de Faria (2002, p. 64-65), foi uma rede de fenômenos políticos e econômicos ${ }^{7}$ no ocidente da década de 1970 que permitiu a ascensão de ambos, enredados no que se convencionou chamar de reestruturação produtiva, vale dizer, um novo arranjo espaço-temporal do trabalho no qual a grande fábrica aos poucos perde a sua prevalência em prol de um paradigma "pós-fordista" ou de "especialização flexível” (LIMA; JUNIOR, 2018, p. 32).

A mobilidade ampliada do capital que tem lugar nesse período histórico favoreceu o seu deslocamento para países com salários mais baixos, com proteção e custo do trabalho reduzidos, acirrando a competição nacional e internacional por investimentos e pressionando os governos a adaptarem-se às demandas empresariais para a geração de empregos (BOURDIEU, 1998, p. 74). Nesse sentido, como aponta Barkin (1998), foram os países periféricos os mais impactados por essa nova divisão internacional do trabalho, ao mesmo tempo em que os países do centro passaram a afrouxar a rede de proteção social para não perderem em competitividade.

Percebe-se, assim, quão profunda é raiz da precarização do trabalho a nível global, podendo-se chamá-la, sem exagero, de estrutural, sobretudo a partir da crise econômica mundial de 2008 (ANTUNES, 2018, p. 26-32). De fato, Standing (2014b, p. 49) aponta que o precariado cresceu por conta de políticas e mudanças institucionais que se seguiram mundialmente aos anos 1970, relacionadas ao compromisso com uma economia de mercado aberta que se associa, inexoravelmente, a um sistema de produção global de empresas em rede e a práticas de emprego flexíveis, não causando espanto a associação da flexibilidade à insegurança.

\footnotetext{
${ }^{7} \mathrm{O}$ autor apresenta as seguintes causas de emergência do novo paradigma de produção a partir da década de 1970, na esteira da globalização econômica: crise do padrão monetário internacional, dois choques consecutivos do petróleo (1973/1974 e 1978/1979), estagnação econômica e processo inflacionário sem precedentes, problemas de liquidez mundial, acentuada queda no preço das commodities, saturação da oferta e da demanda de bens duráveis na Europa ocidental e nos EUA, redução dos níveis de investimento e deterioração das condições de rentabilidade dos capitais tangíveis e intangíveis.
} 
É justamente em razão das colossais e resilientes mutações engendradas pela referida Transformação Global que existem autores a defender um ponto de vista diferente daqueles inspirados pelo marxismo, segundo os quais o neoliberalismo seria uma ideologia ou um grupo de políticas econômicas que implicam a precarização dos direitos sociais. Segundo tal perspectiva, bastante próxima do pensamento de Foucault (2008), o neoliberalismo seria sim uma racionalidade global, um sistema normativo que estende a lógica do capital a todas as relações sociais e esferas da vida (DARDOT; LAVAL, 2016, p. 17-19).

Dardot e Laval (2016, p. 144-155) embasam o já mencionado terceiro "espírito" do capitalismo nessa racionalidade, de modo a resgatar a importância, teorizada por Max Weber, da mobilização da subjetividade e da constituição de um código moral para o funcionamento do capitalismo. Isso porque a precariedade da vida tende a se sustentar, na prática, por um discurso que transforma o trabalhador em empresário de si mesmo, uma nova espécie de "homem do cálculo" que valoriza indistintamente a competição em todas as esferas da vida. Trata-se, enfim, de um discurso que tende a vincular integralmente a subjetividade do obreiro à atividade que se exige que ele cumpra.

É justamente nesse sentido que se orienta o subjetivismo de autores austríacos como Mises (1995), o qual procura remodelar a ação humana (ou social) tendo por referência uma praxeologia no âmbito do mercado como processo subjetivo. O homem-empresa está em processo permanente de concorrência, é um sujeito ativo, construtor, que corre riscos e não mais se contenta com as promessas da cidadania industrial.

Sem embargo, uma vez focalizada a definição do precariado segundo Guy Standing, bem como tendo-se rapidamente exposto o cenário mais amplo no qual a precarização do trabalho se encontra alicerçada, o próximo item é destinado a delimitar de forma juridicamente relevante a precarização do trabalho de forma consentânea com a realidade brasileira.

\section{O PRECARIADO À LUZ DA REALIDADE BRASILEIRA E A SUA SIGNIFICAÇÃO JURÍDICA}

Como destacado anteriormente, as mutações multidiversificadas que ocorrem desde 1970 ensejaram um sistema de produção global de empresas em rede (com protagonismo das transnacionais e sob os influxos da nova divisão internacional do trabalho) e práticas de emprego flexíveis. Nesse diapasão, conforme o exposto por Standing (2014b, p. 56), “a busca de relações de emprego flexíveis tem sido a principal causa direta do crescimento do precariado global". 
Isso significa que o crescimento do precariado, com toda a sua ambiguidade, tem como correlato imediato um fenômeno jurídico, a saber, a flexibilização do direito do trabalho, situação que será tratada com maior ênfase nas páginas subsequentes. Sem embargo dessa constatação, e antes de enveredar por seus caminhos, entende-se como oportuno problematizar a definição precedentemente apresentada de precariado à luz das particularidades socioeconômicas brasileiras.

Para Guy Standing, o precariado seria definido como uma nova classe desprovida de sete formas de garantia relacionadas ao trabalho perseguidas e conquistadas como agenda de "cidadania industrial". Ocorre que essa agenda, que também se identifica com o que Castel (1999, p. 415) denomina "sociedade salarial" ou com o que Harvey (2008, p. 20) chama de "compromisso de classe entre o capital e o trabalho", faz mais sentido no contexto histórico europeu.

Esse "compromisso de classe" do período pós-Segunda Guerra encontra firmes raízes no Welfare State, isto é, na socialdemocracia europeia embasada na aceitação de que o Estado deveria concentrar-se no pleno emprego, no crescimento econômico e no bem-estar de seus cidadãos, o que era perseguido mediante políticas fiscais e monetárias em geral definidas como "keynesianas", que caminhavam lado a lado com padrões de salário social e uma miríade de sistemas de bem-estar (cuidados de saúde, instrução, previdência etc.).

Conforme expõe Ricardo Antunes, nos países centrais, do Norte global, na gênese do movimento operário nasceu também uma forte aristocracia operária e, posteriormente, se desenvolveu um sólido proletariado herdeiro do taylorismo, do fordismo e do Welfare State, de modo que o advento recente do precariado contrastou enormemente com o já existente proletariado tradicional (HARVEY, 2008, p. 20).

Por conseguinte, os bolsões de imigrantes, a crise estrutural, o desemprego, o subemprego e os novos fluxos migratórios, acontecimentos que de modo geral a partir dos anos 1980 se aliaram ao progressivo desmantelamento dos mecanismos do Welfare State, ampliaram significativamente as clivagens dentro da classe trabalhadora nos países centrais, fato que gerou um contraste tão visível nessas localidades a ponto de Standing definir o precariado como uma nova classe, apartada dos trabalhadores tradicionais.

Ocorre que, no Brasil em particular e nos países periféricos do Sul global em geral, esse contraste não foi tão acentuado assim. Antunes (2018, p. 61-62) defende que nas periferias "o proletariado nasceu eivado da condição de precariedade", não sendo pois mera exceção, mas sim "um traço constante de sua particularidade desde a origem", fator intensificado pelo 
escravismo colonial. ${ }^{8}$ Aqui não houve nenhuma sólida aristocracia operária ou tampouco Estado de bem-estar nos moldes estrangeiros, bastando lembrar que enquanto o Welfare State triunfava na Europa a América do Sul amargava ditaduras e perdas de poder aquisitivo. ${ }^{9}$

No mesmo sentido, Vargas (2016, p. 324-325) indica que amplas camadas sociais brasileiras "jamais estiveram integradas a um conjunto de relações de trabalho regulares e estáveis e a um sistema de proteção social”, porquanto nestes trópicos nunca se constituiu a "sociedade salarial” marcada pela generalização da relação laboral estável e protegida. Não por outro motivo Darcy Ribeiro, ao final de sua clássica análise da formação do povo brasileiro, afirmou existir aqui uma força de trabalho "fundada no atraso" (RIBEIRO, 1995, p. 447).

Em verdade, a incapacidade do mercado de trabalho nacional em absorver a força de trabalho da população e gerar o ciclo virtuoso do consumo sempre foi objeto de debate dos economistas e cientistas sociais, já que não raro as teorias do subdesenvolvimento apontavam como uma de suas causas a grande massa de miseráveis subocupados, a qual Singer (2012, p. 18) nomeou, inspirado em Marx, como "sobrepopulação trabalhadora superempobrecida permanente".

Com efeito, existem evidências suficientes para se adotar a visão de Braga (2014, p. 30), segundo o qual o precariado não seria uma nova classe, mas sim "o proletariado precarizado", fração da classe trabalhadora desqualificada ou semiqualificada submetida a altas taxas de rotatividade do trabalho, abarcando jovens em busca do primeiro emprego, indivíduos ocupados instavelmente na informalidade e trabalhadores formais sub-remunerados e inseridos em condições degradantes.

Tal definição, para além de consentânea com a realidade socioeconômica brasileira, adequa-se à nova morfologia da classe trabalhadora contemporânea - que incorpora, segundo Antunes, a totalidade dos trabalhadores assalariados, formais ou informais, produtivos ou improdutivos - e encontra respaldo na própria teorização de Standing (2014b, p. 36), segundo o qual é possível ver o precariado em termos de processos, "a maneira pela qual as pessoas são "precarizadas"”.

Não obstante a precariedade seja um traço distintivo de parcela significativa da população trabalhadora brasileira há muito tempo, mantém-se a relevância do estudo local sobre o precariado nos dias atuais em função do seu crescimento a partir da década de 1990,

\footnotetext{
${ }^{8}$ Para uma crítica africana a Standing, ver Scully (2016).

${ }^{9}$ No Brasil, datam da década de 1970 as primeiras flexibilizações na legislação trabalhista. Para uma análise mais profunda do arrocho salarial imposto durante a ditadura, ver Aguillar (2012, p. 170-172).
} 
impulsionado basicamente por dois fatores: o aumento abrupto da informalidade e o avanço da precarização sobre o emprego formal.

Quanto ao primeiro, as estatísticas oficiais (PNAD do IBGE) indicam que em 1981 os trabalhadores sem carteira assinada correspondiam a $28 \%$ da população ocupada. Apesar de tal percentual se manter relativamente estável no resto da década, a partir de 1990 teve início um processo de elevação sem precedentes no grau de informalidade do mercado de trabalho brasileiro, com um aumento de $10 \%$ ao final dos anos 1990 (ULYSSEA, 2006, p. 596-597). ${ }^{10}$ Atualmente, embora com diferentes critérios, o IBGE contabiliza 43\% de trabalhadores na informalidade (FERNANDES; QUINTINO, 2018). ${ }^{11}$

Quanto ao segundo, nota-se que na última década houve a combinação da formalização do trabalho com a sua concomitante precarização, principalmente sob a forma de cooperativas de trabalho, contratos comerciais e terceirizações. O modelo de desenvolvimento adotado pelo Brasil durante o lulismo aumentou exponencialmente o assalariamento formal ao mesmo tempo que, em média, 94\% dos empregos criados pagavam até 1,5 salário mínimo; em 2014, já em ritmo de desaceleração, cerca de 97,5\% dos novos empregos remuneravam nesse patamar (BRAGA, 2016, p. 88-89).

Em outras palavras, a qualidade do emprego está em queda no país, tendo aumentado o número de acidentes e mortes no trabalho e a taxa de rotatividade. Segundo dados do DIEESE, a taxa global de rotatividade dos celetistas era de 52,4\% em 2003 e aumentou 12 pontos percentuais até 2012, a partir de quando a taxa recuou a números semelhantes ao período anterior a 2007, isto é, mantendo-se elevada apesar da crise econômica (BRAGA, 2016, p. 89).

No que tange à terceirização, o fato é que tal modalidade de contratação cresceu significativamente no Brasil. A propósito, o DIEESE aponta que em 2014, dos 50 milhões de trabalhadores com carteira assinada, 12,7 milhões eram terceirizados. Todavia, os obreiros nessa modalidade recebem em média $24,7 \%$ a menos por uma jornada semanal 7,5 horas mais longa, submetendo-se a uma taxa de rotatividade 53,5\% maior do que aquela dos diretamente contratados (BRAGA, 2017).

Pois bem, consoante as já mencionadas considerações de Standing, o outro lado da moeda do crescimento do precariado é a flexibilização do direito trabalhista, que se relaciona diretamente com a precarização do trabalho formal. De acordo com Uriarte (1992, p. 13), “a

\footnotetext{
${ }^{10}$ Esses números não consideravam o trabalhador por conta própria como informal.

11 Nessa série histórica, considera-se como informais os trabalhadores que não tinham carteira assinada, englobando empregados do setor privado e público sem registro, trabalhadores por conta própria sem CNPJ, trabalhadores domésticos sem carteira e quem labora em família.
} 
proposta flexibilizadora consiste em afrouxar, eliminar ou adaptar, segundo os casos, a proteção laboral clássica", sob a justificativa de contribuir para o aumento do emprego ou da competitividade empresarial, que se acirrou com a globalização.

Tal proposta parte de uma crítica econômica ou economicista à proteção especial do vínculo laborativo, uma vez que a proteção - princípio basilar desse ramo do direito - ou o excesso de proteção produziria um efeito contrário à sua teleologia, de modo a gerar desemprego e desestimular a criação de novos postos de trabalho (URIARTE, 1992, p. 12). Isso porque a racionalidade neoliberal entende a ordem de mercado como uma nomocracia (regida por leis formais e gerais) e não como uma teleocracia (regida por fins), sendo esta última extremamente nociva à ordem espontânea de mercado (DARDOT; LAVAL, 2016, p. 162).

Essas teorias, nas palavras de Uriarte (1992, p. 14), passam a considerar o direito do trabalho um instrumento de auxílio à superação das crises econômicas, fazendo-se necessário distinguir a flexibilidade real da flexibilidade jurídica, porquanto a primeira alude à necessidade adaptativa da produção às novas tecnologias e às novas necessidades do consumidor, enquanto a segunda significa um apoio normativo à primeira, nem sempre estritamente necessário.

Standing (2014b, p. 56-77) entende esse fenômeno jurídico como um processo de "mercadorização" da força de trabalho, dividindo-o em três formas de flexibilidade: 1) numérica, 2) funcional e 3) salarial. A primeira envolve o enfraquecimento da proteção ao vínculo empregatício através de contratos atípicos (terceirização, temporário, estágio etc.) ou facilitações à demissão; a segunda fomenta a insegurança no emprego, permitindo realocações rápidas e sem custo às empresas no que toca à gestão do trabalho e sua divisão; a terceira, por fim, implica a variabilidade da renda e o incremento da sua imprevisibilidade.

Por conseguinte, uma vez definido o precariado de modo coerente com as peculiaridades brasileiras e do Sul global, bem como estabelecida a faceta jurídica - e também as motivações econômicas - do crescimento dessa fração de classe, tem-se plenas condições de se abordar a reforma trabalhista brasileira de 2017.

\section{PRECARIADO E A FLEXIBILIZAÇÃO CONTEMPORÂNEA DO DIREITO DO TRABALHO PÁTRIO}

A denominada reforma trabalhista brasileira, implementada pelas leis $\mathrm{n}^{\circ}$ 13.429/2017 e 13.467/2017, tem como eixo central a proposta flexibilizante, definida anteriormente com a análise de Oscar E. Uriarte, segundo a qual o direito do trabalho passa a ser um locus privilegiado para a superação da crise e a geração de emprego e renda, desde que "modernizada" 
em sua rigidez e imperatividade, incrementando mobilidade e poder negocial aos contratantes sem intermediação de terceiros.

Krein (2018, p. 87) condensa o conteúdo dessa reforma de acordo com as suas novidades 1) em relação aos direitos, no que concerne às 1.1) formas de contratação e facilidade para despedir, 1.2) jornada de trabalho, 1.3) remuneração da jornada, 1.4) condições de trabalho em termos de segurança e saúde pública; 2) em relação ao papel de instituições públicas no que se refere 2.1) à regulamentação da representação dos interesses coletivos e da negociação coletiva, 2.2) às limitações de acesso à Justiça do Trabalho e 2.3) ao engessamento do sistema de fiscalização de fraude.

Seguindo esse mesmo mapa interpretativo, é possível colocar em relevo, sem discutir juridicamente a sua compatibilidade com o ordenamento, as principais alterações legislativas que oferecem incentivos institucionais aos empregadores no sentido da precarização do ser vivente assalariado.

Em primeiro lugar, a pulverização das formas de contratação, com a inédita possibilidade de terceirização da atividade-fim (art. $4^{\circ}$-A da Lei ${ }^{\circ}$ 6.019/74), a ampliação do contrato a tempo parcial com possibilidade de jornada extraordinária (art. 58-A CLT), a introdução do contrato de trabalho intermitente (art. 443, $\S 3^{\circ}$, CLT), a extensão do período do contrato temporário (art. $10, \S 1^{\circ}$ e $\S 2^{\circ}$, Lei $\left.n^{\circ} 6.019 / 74\right)$ e o surgimento da figura do "autônomo permanente", que não se enquadra no regime jurídico celetista (art. 442-B CLT).

Despiciendo dizer que tal pulverização tende a tornar o vínculo empregatício mais precário, rotativo e mal remunerado, dificultando o acesso dos obreiros menos especializados ao efetivo gozo de direitos que dependem da continuidade, a uma identidade profissional segura e a um senso de carreira; em contrapartida, as novas modalidades contratuais facilitam a adequação da atividade empresarial aos ciclos econômicos e diminuem os encargos trabalhistas relacionados aos salários, o que em tese fomenta a criação de trabalho formais.

Mauricio G. Delgado afirma que o princípio da continuidade na relação de emprego favorece a afirmação social do indivíduo a ele vinculado, o qual não raro vive exclusivamente de seu trabalho e renda que dele aufere; dessa maneira, a submissão do obreiro a um contrato precário ou de curta duração lhe retira "o lastro econômico e jurídico necessário para se impor no plano de suas demais relações econômicas na comunidade". Sem embargo, a longa permanência no emprego também colabora para a tendencial elevação dos direitos trabalhistas (por legislação e negociações coletivas ou por promoções e outras vantagens individuais) e para a educação e aperfeiçoamento do empregado (DELGADO, 2017, p. 224). 
Em segundo lugar, as mudanças introduzidas a propósito da jornada de trabalho, com a ampliação dos mecanismos de compensação das jornadas por meio de banco de horas, por acordo individual inclusive (art. 59, $\$ 5^{\circ}$ e $\$ 6^{\circ}$ CLT) a regulamentação da jornada $12 \times 36$ jornada diária acima do teto constitucional - para todos os setores (art. 59-A CLT), a possibilidade de parcelamento de férias em até três períodos nunca inferiores a 5 dias (art. 134, $\S 1^{\circ}$, CLT), a possibilidade de negociação do tempo de intervalo para refeição a períodos inferiores a 1 hora (art. 611-A, III, CLT) e o não cômputo das horas in itinere na jornada paga (art. 58, $\left.\$ 2^{\circ} \mathrm{CLT}\right)$.

Essas novidades também são benéficas aos empregadores, uma vez que o tempo do trabalhador passa a ser mais facilmente manejável, abre-se novas possibilidades de extensão da jornada, desincumbe-se o patrão do pagamento de verbas a que estava vinculado e tendem a estimular maior intensidade no labor (DELGADO, 2017, p. 89). Pelo lado do trabalhador, é possível que na prática haja o recrudescimento da insegurança em sua gestão temporal, da sua vida pessoal e da sua família, deixando-o à mercê dos interesses e prioridades do empregador.

O terceiro ponto que merece destaque é referente à remuneração, já que a reforma trabalhista estimula a variabilidade salarial mediante a possibilidade de remuneração mediante bens, bônus e serviços, de forma apartada do salário (art. 457, §2 $2^{\circ} \mathrm{CLT}$ ), de pagamento por desempenho individual ou produtividade (art. $457, \S 4^{\circ} \mathrm{CLT}$ ) e incentiva a adoção do programa de Participação nos Lucros e Resultados (art. 611-A, XV, CLT).

A nova regulamentação tem efeitos diversificados: reduz os custos dos empregadores por flexibilizar as parcelas salariais e evitar a incidência de contribuições sociais, possibilitam que os empresários modulem com maior facilidade a remuneração à situação financeira momentânea e, ao mesmo tempo, a renda social tende a ficar mais instável e insegura, com prejuízo às políticas públicas que utilizavam recursos oriundos das contribuições sociais. Além disso, com a fragmentação das formas de remuneração além do salário, sobre elas não incidirá eventual majoração na eventualidade de reajustes obtidos pela categoria profissional, particularidade que implicará, progressivamente, o achatamento dos salários.

Por fim, o último aspecto digno de nota de acordo com o recorte temático do presente estudo diz respeito à representação sindical, tendo em vista as inovações no sentido da prevalência do negociado sobre o legislado (com limites de ordem pública) (art. 611-A e 611B da CLT), o fim da contribuição sindical obrigatória (art. 535, CLT), a possibilidade de negociação contratual individual com prevalência sobre a lei independentemente da participação do sindicato para "altos empregados" (art. 444, parágrafo único, CLT), a desnecessidade de homologação do sindicato quando da rescisão contratual (revogação do art. 
$\left.477, \S 1^{\circ}, \mathrm{CLT}\right)$ e a representação de trabalhadores em empresas com mais de 200 empregados sem a intervenção do ente sindical e sem as antigas estabilidades (art. 510-A e ss., CLT).

Uma parcela da literatura especializada em ciências econômicas afirma que a legislação trabalhista (no que tange à rigidez do disciplinamento contratual, individual ou coletivo) anterior à reforma era uma das causas institucionais do alto índice de informalidade laboral (CAMARGO, 1996; TIRYAKI, 2008). Nessa perspectiva, a flexibilização normativa aprovada recentemente pelo Parlamento poderia representar um incentivo à formalização do trabalho e, por conseguinte, à melhoria das condições de vida dos trabalhadores e trabalhadoras informais mais vulneráveis. ${ }^{12}$

No âmbito jurídico, Martins Filho (2017, p. 19-29) segue essa mesma linha interpretativa ao aduzir que a reforma trabalhista é dotada de enorme importância macroeconômica para superar "a falência do Estado brasileiro, da previdência social e das empresas, com 13 milhões de desempregados", uma vez que diminui o intervencionismo estatal nas relações de trabalho e incentiva o desenvolvimento rentável da atividade empresarial.

Nessa mesma senda, Barroso e Mello (2018, p. 21-46) criticam duramente a velha sistemática normativa da Consolidação das Leis Trabalho em termos de direito coletivo, denominando como "paternalista" a corrente jurisprudencial que invalidava acordos coletivos de trabalho com base em uma lógica de limitação da autonomia da vontade, a qual somente seria aplicável ao direito individual do trabalho. Para os autores, assim, as negociações laborais coletivas seriam privilegiadas pela Constituição e poderiam sobrepor-se à legislação vigente, o que foi acatado, como se viu, pela reforma trabalhista.

De acordo com tais reflexões, as leis $n^{\circ} 13.429 / 2017$ e $13.467 / 2017$ podem ter papel fundamental na instauração de um novo marco regulatório para as relações de trabalho no Brasil, incentivando a saída da crise econômica, a retomada da geração de empregos e a consequente geração de renda com diminuição das desigualdades, tendo o grande mérito de conectá-las ao atual paradigma do sistema produtivo e à legislação de países desenvolvidos.

Sem embargo dessas possíveis interpretações, perfeitamente fundamentadas pelos seus autores, a adoção do ponto de vista do precariado na análise dessa reforma tem o grande mérito de suscitar novos elementos ao debate. Isso porque, ainda que se admita a possibilidade de que a nova legislação venha a contribuir, futuramente, para a diminuição da informalidade e para a

\footnotetext{
12 Exemplo etnográfico interessante dessa parcela é apresentado por Souza (2018, p. 263-300), que cunhou esses trabalhadores de "ralé brasileira".
} 
geração de empregos - o que é contestado por diversos outros estudiosos ${ }^{13}$-, a qualidade desses novos vínculos empregatícios remanescerá uma incógnita.

Consoante a exposição precedente, o precariado deve ser apreendido de forma dinâmica, como um processo pelo qual as pessoas que vendem a força de trabalho são precarizadas. Não se trata simplesmente de um grupo de pessoas destituído de estabilidade e cobertura da previdência social - eis que essa é a regra em países periféricos como o Brasil -, mas de uma fração da classe jovem, desqualificada ou semiqualificada, cada vez mais submetida a altas taxas de rotatividade, ocupada instavelmente na informalidade ou formalmente empregada sob condições degradantes e sub-remuneradas. ${ }^{14}$

A partir dessa definição, e com o auxílio das teorizações de Standing, nota-se que a insegurança (de renda, emprego, moradia, cobertura social), a ausência de possibilidade de construção de uma identidade profissional segura e de um senso de carreira são traços marcantes na vida de seus integrantes. O que impera é o "curto-prazismo" da vida líquida identificada por Bauman, propulsionada pelo ethos do terceiro "espírito" do capitalismo, o qual valoriza uma vida baseada na competitividade, meritocracia, flexibilidade e empreendedorismo:

\begin{abstract}
A vida líquida é uma "vida precária", em "condições de incerteza constantes", permeada de "constantes reinícios" e aonde não se pode ficar parado (modernizar-se ou perecer): "é uma vida de consumo". Vivemos em uma "sociedade de indivíduos", na qual "todos os problemas em que podemos nos meter são assumidos como criados por nós mesmos" (LIMA, 2016, p. 31-32).
\end{abstract}

Outra característica do precariado é a impossibilidade de captá-lo pelo ferramental jurídico tradicional do direito do trabalho, porquanto engloba trabalhadores tanto informais (não celetistas) quanto formais; ademais, o que se encara sociologicamente como precarização - ampla rotatividade, sub-remuneração, condições de trabalho degradantes - encontra aprioristicamente respaldo jurídico na possibilidade de demissão ad nutum, no respeito ao salário mínimo e no poder diretivo do empregador, desde que dentro dos limites legais.

Portanto, o que se encara como precarização da vida sob o ponto de vista das ciências sociais ou da psicologia normalmente é revestido pelo manto da legalidade e do eficientismo econômico, devendo-se procurar nos interstícios da legislação, nas franjas da regulação estatal, os incentivos à sociedade civil para a fabricação de sujeitos trabalhadores com modo de vida precário (DARDOT; LAVAL, 2016, p. 321-376). É no centro dessa constatação que se pode

\footnotetext{
${ }^{13}$ Para exemplificar, veja-se que é esse o posicionamento de Peter Poschen, diretor da OIT no Brasil, segundo o qual a experiência internacional demonstrou haver poucas evidências de que a flexibilização da legislação trabalhista gere os empregos propalados por seus apoiadores (MURAKAWA, 2017).

${ }^{14} \mathrm{O}$ estudo de Braga $(2014$, p. 30) aponta a sub-remuneração como inferior a 1,5 salário mínimo.
} 
entender a reforma trabalhista como um incentivo à manutenção ou ao crescimento do precariado nacional.

Nesse contexto, vale ressaltar, consoante os ensinamentos de Barbosa (2016), que o mercado de trabalho brasileiro, por sua condição periférica, historicamente apresenta as características de má remuneração ao trabalhador, rotatividade elevada, disparidade nos rendimentos e precariedade das condições laborais, o que não mudou com o bom momento econômico do início do século XX e o aumento da formalização da mão de obra, como se viu no item 3 do presente estudo.

Portanto, essas características estruturais do mercado de trabalho local não vão simplesmente desvanecer por meras inovações legais. Ademais, o grande ponto, aqui, é que a reforma trabalhista está inteiramente calcada na redução de custos à atividade empresarial e na descentralização do processo de definição das regras da regulação de emprego para o interior da empresa. Em outras palavras, sua mensagem é a de que o sucesso macroeconômico depende de trabalhadores mais inseguros e autossuficientes na relação empregatícia.

O principal motivo para essa interpretação não reside primordialmente na flexibilização das formas de remuneração, da representação sindical ou da jornada - embora elas possam contribuir globalmente para o fenômeno -, mas sim na pulverização das formas de contratação: com o propósito de gerar empregos para superar a crise, justifica-se o incentivo estatal à criação de vínculos precários que não oferecem qualquer perspectiva ou identificação profissional, demasiadamente instáveis e que dificultam sobremaneira o acesso do trabalhador a direitos cujo gozo efetivo depende da continuidade no emprego.

É plausível crer que a reforma ocasione a expansão da terceirização - o que significa mais trabalho, pior remuneração e maior rotatividade, de acordo com os números do DIEESE anteriormente mencionados -, da pejotização - com a figura do "autônomo exclusivo" -, do trabalho intermitente - na prática, a formalização do "bico" - e do trabalho temporário. Embora esse prognóstico possa forçar para baixo a informalidade - o que até hoje, dois anos após as mudanças, ainda não ocorreu -, fato é que a maior flexibilidade tem como preço o aumento da precariedade, para o bem e para o mal. Em suma, ao que tudo indica essa precariedade é a sina do trabalhador que compartilha o ethos do capitalismo global contemporâneo.

\section{CONSIDERAÇÕES FINAIS}

Os argumentos apresentados neste artigo destinaram-se a demonstrar a complexidade envolta nos atuais debates sobre a reforma trabalhista brasileira. Foi possível perceber, com o 
auxílio das ciências sociais e do profícuo debate interdisciplinar, que a flexibilização do direito do trabalho não se circunscreve a uma mera questão legal, bem como que o marco regulatório do labor humano implantado pelo Estado influi diretamente na concretude da vida dos sujeitos trabalhadores e trabalhadoras mediante seus incentivos diretos e indiretos.

As recentes alterações legislativas, como se viu, são plenamente consentâneas com a ética (ou o "espírito") do capitalismo contemporâneo e até mesmo - não se pode negar - vão de encontro aos anseios de indivíduos que pleiteiam maior maleabilidade no trabalho e na gestão pessoal do tempo; além disso, existem economistas e juristas que argumentam a imperiosa necessidade dessa reforma para a melhora dos índices de crescimento, ocupação formal e desenvolvimento do país, de modo a considerar o direito como um importante instrumento de maximização da eficiência econômica.

No entanto, para a melhor aplicação do direito, em sintonia com os avanços e conquistas democráticas das classes subalternas sobretudo ao longo do século XX, é necessário despir-se da racionalidade instrumental e notar as nuances desse fenômeno: a flexibilização do arcabouço normativo trabalhista tem como efeito colateral inevitável uma evidente tendência à precariedade crescente dos trabalhadores brasileiros, o que, embora não seja novidade na América Latina, passa agora a ser estimulada pelo Estado.

Nesse contexto, objetivou-se apresentar o precariado no Brasil, não apenas como uma nova classe, nos termos de Standing, mas sobretudo como uma fração de classe que pode vir a aumentar significativamente no Brasil principalmente pela via das novas modalidades contratuais, cujo efeito principal será prejudicar a continuidade do vínculo empregatício caso a sua utilização de fato se generalize no mercado.

Disso não podem descurar sequer os defensores da proposta flexibilizante, merecendo especial atenção dos operadores do direito e dos gestores públicos, responsáveis pela elaboração de políticas públicas para essa parcela significativa de cidadãos, potencialmente mais próximos da pobreza e da vulnerabilidade socioeconômica, sob pena de dar-se respaldo a um hediondo retrocesso civilizacional, social e jurídico.

\section{REFERÊNCIAS BIBLIOGRÁFICAS}

AGUILLAR, F. H. Direito econômico: do Direito Nacional ao Supranacional. 3 ed. São Paulo: Atlas, 2012.

ANTUNES, R. O privilégio da servidão: o novo proletariado de serviços na era digital. São Paulo: Boitempo, 2018. 
BARBOSA, A. de F. O mercado de trabalho: uma perspectiva de longa duração. Estud. av., São Paulo, v. 30, n. 87, p. 7-28, Ago. 2016. Disponível em: http://www.scielo.br/pdf/ea/v30n87/0103-4014-ea-30-87-00007.pdf. Acesso em: 16/01/2019.

BARKIN, D. Proletarización global: un acercamiento a la nueva división internacional del trabajo. Economia, sociedad e território, Toluca, v.1, n.3, p. 429-455, enero-junio de 1998. Disponível em: https://www.redalyc.org/articulo.oa?id=11110301. Acesso em: 09/01/2019.

BARROSO, L. R.; MELLO, P. P. C. O direito coletivo do trabalho no Supremo Tribunal Federal: Planos de demissão incentivada e autonomia da vontade, um estudo de caso. Revista de Direito do Trabalho, São Paulo, v. 190, jun. 2018. p. 21-46.

BOLTANSKI, L.; CHIAPELLO, E. O novo espírito do capitalismo. São Paulo: Martins Fontes, 2009.

BOURDIEU, P. Contrafogos: táticas para enfrentar a invasão neoliberal. Rio de Janeiro: Jorge Zahar, 1998.

BRAGA, R. Precariado e sindicalismo no Brasil contemporâneo: um olhar a partir da indústria do call center. Revista Crítica de Ciências Sociais, Coimbra, n. 103, Maio 2014. p. 25-52. Disponível em: http://www.scielo.mec.pt/pdf/rccs/n103/n103a03.pdf. Acesso em: 11/01/2019.

BRAGA, R. Terra em transe: o fim do lulismo e o retorno da luta de classes. In: SINGER,A.; LOUREIRO, I. As contradições do lulismo: a que ponto chegamos? São Paulo: Boitempo, 2016.

BRAGA, R. A rebeldia do precariado: trabalho e neoliberalismo no Sul global. São Paulo: Boitempo, 2017.

CAMARGO , J. M. Flexibilidade e produtividade do mercado de trabalho brasileiro. In

(Org.). Flexibilidade do mercado de trabalho no Brasil. Rio de Janeiro: Editora Fundação Getúlio Vargas, 1996.

CASTEL, R. As metamorfoses da questão social: uma crônica do salário. Petrópólis: Vozes, 1999.

DARDOT, P.; LAVAL, C. A nova razão do mundo: ensaio sobre a sociedade neoliberal. São Paulo: Boitempo, 2016.

DELGADO, M. G. Curso de Direito do Trabalho. São Paulo: LTr, 2017.

DIEESE. Movimentação no mercado de trabalho: rotatividade, intermediação e proteção ao emprego. São Paulo: DIEESE, 2017. p. 82. Disponível em: https://www.dieese.org.br/livro/2017/rotatividade.pdf. Acesso em: 12/01/2019.

FARIA, J. E. O direito na economia globalizada. São Paulo: Malheiros, 2002.

FERNANDES, A.; QUINTINO, L. Informalidade bate recorde no país e já atinge $43 \%$ dos trabalhadores. Folha de São Paulo, 3 nov. 2018. Disponível em: 
https://www1.folha.uol.com.br/mercado/2018/11/informalidade-bate-recorde-no-pais-e-jaatinge-43-dos-trabalhadores.shtml?loggedpaywall. Acesso em: 12/01/2019.

FOUCAULT, M. O nascimento da biopolítica. São Paulo: Martins Fontes, 2008.

HARVEY, D. O neoliberalismo: história e implicações. São Paulo: Edições Loyola, 2008.

KALLENBERG, A. L. O crescimento do trabalho precário: um desafio global. Revista brasileira de ciências sociais, São Paulo, n. 69, v. 24, fevereiro/2009. p. 21-30. Disponível em: http://www.scielo.br/scielo.php?script=sci_arttext\&pid=S0102-69092009000100002. Acesso em: 09/01/2019.

KREIN, J. D. O desmonte dos direitos, as novas configurações do trabalho e o esvaziamento da ação coletiva: consequências da reforma trabalhista. Tempo social, Revista de Sociologia da USP, São Paulo: v. 30, n. 1. p. 77-104. Disponível em: http://www.scielo.br/pdf/ts/v30n1/18094554-ts-30-01-0077.pdf. Acesso em: 13/01/2019.

LIMA, A. L. C. de. Globalização econômica, política e direito: análise das mazelas causadas no plano político-jurídico. Porto Alegre: Sérgio Antonio Fabris, 2002.

LIMA, A. L. As consequências sociais e jurídicas da modernidade líquida: reflexões sobre a globalização e o direito a partir de Zygmunt Bauman. In: BENEDETTI, A. R. de M. et al. Reflexões de filosofia do direito e a filosofia da libertação. Curitiba: Íthala, 2016.

LIMA, J.C.; JUNIOR, A. M. Mobilidades diferenciadas e ilegalidades institucionalizadas: tendências e contradições do trabalho na contemporaneidade. São Paulo, Tempo social, revista de sociologia da USP, v. 30. n. 1. p. 31-51. Disponível em: http://www.scielo.br/pdf/ts/v30n1/1809-4554-ts-30-01-0031.pdf. Acesso em: 09/01/2019.

MARTINS FILHO, I. G.da S. A reforma trabalhista no Brasil. Revista de Direito do Trabalho, São Paulo, v. 181, p. 19-29, set. 2017.

MISES, L. V. A ação humana: um tratado de economia. 2 ed. Rio de Janeiro: Instituto Liberal, 1995.

MURAKAWA, F. Para diretor da OIT, legislação deve prevalecer sobre acordos. Valor econômico, 07 de abr. 2017. Disponível em: https://www.valor.com.br/politica/4930506/paradiretor-da-oit-legislacao-deve-prevalecer-sobre-acordos. Acesso em: 16/01/2019.

REFORMA trabalhista: Temer diz que nova lei 'amplia horizontes' para o emprego e critica 'falsas informações' sobre o tema. G1 Política. Disponível em: https://g1.globo.com/politica/noticia/reforma-trabalhista-temer-afirma-que-nova-lei-ampliahorizontes-para-quem-procura-emprego.ghtml. Acesso em: 23/01/2019.

RIBEIRO, D. O povo brasileiro: a formação e o sentido do Brasil. São Paulo: Companhia das Letras, 1995, p. 447.

SENNETT, Richard. A corrosão do caráter: as consequências pessoais do trabalho no novo capitalismo. Rio de Janeiro: Record, 1999. 
SINGER, A. Os sentidos do lulismo: reforma gradual e pacto conservador. São Paulo: Companhia das Letras, 2012.

SOUZA, J. A ralé brasileira: quem é e como vive. 3 ed. São Paulo: Contracorrente, 2018.

STANDING, G. A precariat charter: from denizens to citizens. Londres: Bloomsbury, 2014a.

STANDING, G. O precariado: a nova classe perigosa. Belo Horizonte: Autêntica Editora, 2014b.

TIRYAKI, G. F. A informalidade e as flutuações na atividade econômica. Revista Estudos Econômicos, São Paulo, v. 38, n.1, jan./mar. 2008. p. 97-125. Disponível em: http://www.scielo.br/pdf/ee/v38n1/05.pdf. Acesso em: 15/01/2019.

URIARTE, O. E. La flexibilidad del Derecho Laboral en algunas experiencias comparadas. Ius et veritas, Lima, n. 4, 1992. p. 12-19. Disponível em: http://revistas.pucp.edu.pe/index.php/iusetveritas/article/view/15324/0. Acesso em: 12/01/2019.

ULYSSEA, G. Informalidade no mercado de trabalho brasileiro: uma resenha da literatura. Revista de economia política, v. 26, n. 4, outubro-dez. de 2006. p. 596-618. Disponível em: http://www.scielo.br/pdf/rep/v26n4/08.pdf. Acesso em: 12/01/2019.

VARGAS, F. B. Trabalho, emprego, precariedade: dimensões conceituais em debate. Caderno CRH, Salvador, v. 29, n. 77, Maio/Ago. 2016. p. 313-331. Disponível em: http://www.scielo.br/pdf/ccrh/v29n77/0103-4979-ccrh-29-77-0313.pdf. Acesso em: $11 / 01 / 2019$.

WEBER, M. A ética protestante e o "espírito" do capitalismo. São Paulo: Companhia das Letras, 2004.

WEBER, M. Economia e sociedade. V. 1. Brasília: UNB, 2004.

Submissão em 23/02/2019 / Aceito em 19/05/2021 